\title{
PUNA-APILAN SIEMENTUHOLAISTEN ESIINTYMINEN JA RUNSAUS SUOMESSA V. 1936
}

\author{
Martti Markkula ja Otto Valle \\ Maatalouden tutkimuskeskus, tuhoeläintutkimuslaitos ja kasvinviljely- \\ laitos, Tikkurila
}

Saapunut 8. 7. 1959

Hankkijan kasvinjalostuslaitoksella Tammistossa (Hels. pit.) työskennellessään hankki kirjoittajista toinen (Valle) v. 1936 maanviljelysseurojen välityksellä yli 200 mykerönäytettä puna-apilasta. Näytteet sijoitettiin kasvatuslaatikoihin joiden lasiputkiin kerääntyneet hyönteiset otettiin talteen. Kasvatuslaatikot pidettiin kasvinjalostuslaitoksen ullakolla. - Samanlaisia apilan siementuholaisten kasvatus- ja runsaudenmääritysmenetelmiä on käytetty eräissä muissakin tutkimuksissa $(1,3$ ja 4$)$.

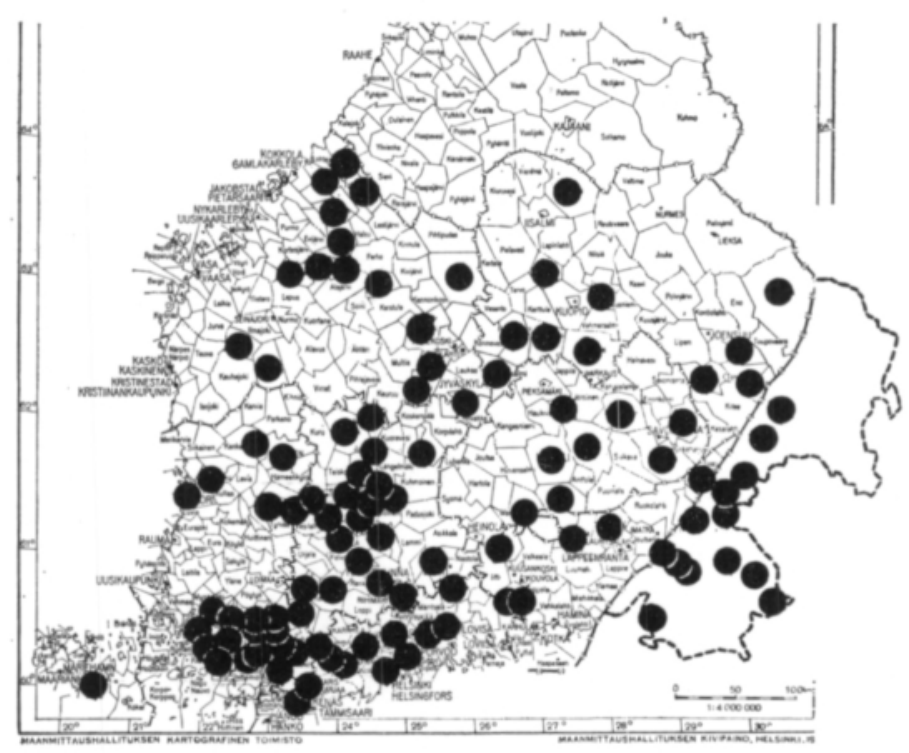

Kuva 1. V. 1936 hankittu puna-apilan mykerönäyteaineisto. Mustalla ympyrällä on merkitty ne pitäjät, joista näytteitä saatiin.

Fig. 1. Red clover flower head material obtained in 1936. The black circles indicate the communes from which samples were obtained. 
Aineiston antamia tuloksia on osittain käytetty hyväksi eräissä aikaisemmissa VALLEn julkaisuissa (5, 6 ja 7). Niissä on kuitenkin voitu esittää ainoastaan eräitä yleispiirteisiä tietoja, koska aineistoon kuuluvien hyönteisten lajinmääritys on ollut aikaisemmin vain puutteellisesti suoritettu.

Syksyllä 1958 toinen kirjoittajista (Markkula) suoritti talletetun hyönteisaineiston lajinmäärityksen. Säilytyksen aikana oli osa aineistoa tuhoutunut. Tässä julkaisussa käsiteltävään aineiston käyttökelpoiseen osaan kuuluu 188 punaapilan mykerönäytettä 111 pitäjän alueelta (kuva 1). Näytteet käsittivät yleensä 100 mykeröä. Kaikkien näytteiden analyysitulokset on esitetty 100 mykeröä vastaavina.

Tulosten julkaiseminen vielä näin myöhään on katsottu aiheelliseksi nimenomaan sen vuoksi, että ne muodostavat mielenkiintoisen vertailukohteen Tuhoeläintutkimuslaitoksella suoritettaville, maamme puna-apilan tuholaisfaunaa ja sen runsautta koskeville selvittelyille, joista osia on jo julkaistu (1 ja 3).

Taulukko 1. Apion apricansin ja A, assimilen runsaus maanviljelysseurojen alueilla v. 1936. Kukin näyte 100 puna-apilan mykeröă. Maanviljelysseurojen sijainti ilmenee kuvasta 2.

Table 1. Abundance of $A p i o n$ apricans and A. as $i$ mile in Agricultural Association districts in 1936. Each sample consisted of 100 red clover flower heads. The location of the districts is shown in Fig. 2.

\begin{tabular}{|c|c|c|c|c|c|c|c|c|c|c|}
\hline & & & & & $\begin{array}{r}\text { Apion } \\
\text { ai } \\
a\end{array}$ & $\begin{array}{l}\text { pricans } \\
\text { sia } \\
\text { lts }\end{array}$ & $\begin{array}{r}\text { Apion } \\
\text { aik } \\
\text { aa }\end{array}$ & $\begin{array}{l}\text { simile } \\
\text { ia } \\
s\end{array}$ & $\begin{array}{r}\text { A. apri } \\
\text { A. as } \\
\text { aikı } \\
\text { adt }\end{array}$ & $\begin{array}{l}\text { ans + } \\
\text { imile } \\
\text { isia } \\
\text { lts }\end{array}$ \\
\hline $\begin{array}{c}\text { Maanviljelysseura } \\
\text { Agricultural Association }\end{array}$ & 莺 & है & 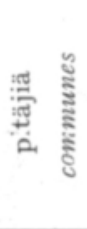 & 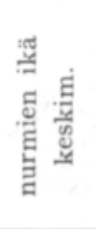 & $\begin{array}{l}3 \\
3 \\
0 \\
0 \\
0 \\
0 \\
0 \\
0 \\
0 \\
0 \\
0 \\
0\end{array}$ & 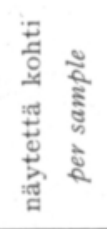 & $\begin{array}{l}\text { डี } \\
\vdots \\
\dot{z} \\
\dot{z}\end{array}$ & 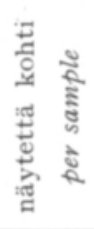 & 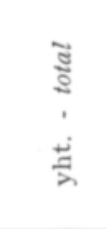 & 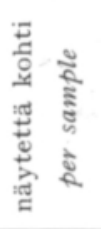 \\
\hline 1. Uudenmaan ja & & & & & & & & & & \\
\hline Hämeen läänin & 8 & & 4 & 2.0 & 113 & 14.1 & 26 & 3.3 & 139 & 17.4 \\
\hline 2. Uudenmaan läänin & 17 & & 11 & 1.6 & 727 & 42.8 & 86 & 5.1 & 813 & 47.8 \\
\hline 3. Suomen talousseura & 4 & & 3 & ? & 180 & $(45.0)$ & 9 & $(2.3)$ & 189 & $(47.3)$ \\
\hline 4. Varsinais-Suomen & 30 & & 15 & 1.7 & 872 & 29.1 & 133 & 4.4 & 1005 & 33.5 \\
\hline 5. Hämeen läänin & 10 & & 8 & 1.8 & 138 & 13.8 & 53 & 5.3 & 191 & 19.1 \\
\hline 6. Satakunnan & 11 & & 5 & 2.0 & 55 & 5.0 & 48 & 4.4 & 103 & 9.4 \\
\hline 7. Hämeen-Satakunnan & 16 & & 12 & 2.0 & 551 & 34.4 & 235 & 14.7 & 786 & 49.1 \\
\hline 8. Itä-Hämeen & 5 & & 2 & $(2.0)$ & 18 & $(3.6)$ & 18 & $(3.6)$ & 36 & $(7.2)$ \\
\hline 9. Mikkelin läänin & 9 & & 8 & 2.1 & 819 & 91.0 & 438 & 48.7 & 1257 & 139.7 \\
\hline 10. Keski-Suomen & 12 & & 7 & 1.8 & 611 & 50.9 & 209 & 17.4 & 820 & 68.3 \\
\hline 11. Etelä-Pohjanmaan & 7 & & 5 & 1.6 & 38 & 5.4 & 27 & 3.8 & 65 & 9.3 \\
\hline 12. Keski-Pohjanmaan & 7 & & 5 & 1.3 & 279 & 39.9 & 127 & 18.1 & 406 & 58.0 \\
\hline 13. Kuopion läänin & 11 & & 6 & 1.9 & 800 & 72.7 & 589 & 53.5 & 1389 & 126.3 \\
\hline 14. Pohjois-Karjalan & 5 & & 4 & 1.3 & 408 & 81.6 & 143 & 28.6 & 551 & 110.2 \\
\hline 15. Viipurin lăänin & 17 & & 10 & 1.9 & 1441 & 84.8 & 180 & 10.6 & 1621 & 95.4 \\
\hline 16. Itä-Karjalan & 19 & & 6 & 1.8 & 1046 & 55.1 & 322 & 16.9 & 1368 & 72.0 \\
\hline $\begin{array}{l}\text { Yht. ja keskim. } \\
\text { Total and average }\end{array}$ & 188 & & 111 & 1.8 & 8196 & 43.1 & 2643 & 14.1 & 10739 & 57.2 \\
\hline$\%$ & & & & & 75.4 & & 24.6 & & 100.0 & \\
\hline
\end{tabular}




\section{Tulokset}

Näytteistä kehittyi seuraavien nirppulajien (Apion) aikuisia: apilanirppu (A. apricans Herbst), pieni apilanirppu (A. assimile Kirby), lounainen apilanirppu (A. trifolii L. = A. aestivum Germ.) ja keltasäärinirppu (A. flavipes Payk.). Kahden ensiksi mainitun lajin yksilöitä oli kaikkiaan 10739 , joista apilanirppua $3 / 4$ ja pientä apilanirppua $1 / 4$ (taulukko 1). Nämä olivat aineiston runsaslukuisimmat hyönteiset. Kaikkien maanviljelysseurojen alueilla apilanirppu oli vähintään yhtä runsaslukuinen kuin pieni apilanirppu. Ensin mainitun lajin suurimmat runsausluvut olivat maan keski- ja itäosissa sijaitsevien maanviljelysseurojen alueilla. Viimeksi mainittu oli runsaslukuisin maan keskiosissa (Kuopion ja Mikkelin läänin maanviljelysseurat). Lajien yhteenlaskettu runsaus oli näin ollen suurin maan keskija itäosissa. Maan länsiosissa molemmat lajit olivat vähälukuisia (kuva 2).

Hankkijan kasvinjalostuslaitoksen Tammiston puna-apilanurmista v. 1936 otettuja mykerönäytteitä tarkastettiin $10 \mathrm{kpl}$. Apilanirppua ja pientä apilanirppua oli yhteensä 514 yksilöä, josta viimeksi mainittua $64 \%$. Myös vuosina 1956-1958 Tuhoeläintutkimuslaitokselle Hankkijan kasvinjalostuslaitokselta hankituissa näytteissä on ollut pientä apilanirppua. VALLE on julkaisuissaan (5, 6 ja 7$)$ maininnut vain apilanirpun. Nyt suoritetut lajinmääritykset osoittavat, että apilanirpun

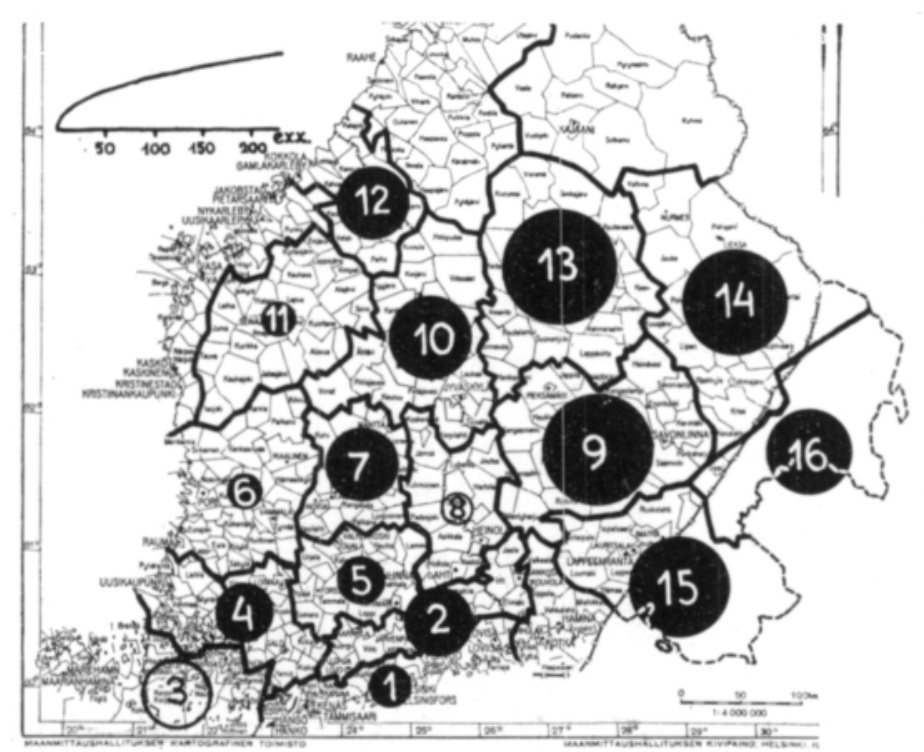

Kuva 2. Apilanirpun (Apion apricans) ja pienen apilanirpun (A. assimile) yhteenlaskettu runsaus maanviljelysseurojen alueilla. Mustan ympyrän suuruus ilmoittaa keskimääräisen, yksilörunsauden mykerönãytettä (100 mykeröä) kohti. Ympyrän keskellä oleva luku ilmoittaa maanviljelysseuran järjestysnumeron (kts. taulukko 1). Avoin ympyrä on merkitty niiden maanviljelysseurojen kohdalle, joista saatujen näytteiden määrä on hyvin vähäinen.

Fig. 2. Occurrence of two species of clover weevils, Apion apricans and A. as simile, found in various Agricultural Association districts. The size of the black circle shows the average abundance of weevils per sample of 100 heads. The figure in the circle refers to the number of the Africultural association (Table 1). The open circles indicate the associations where the number of samples obtained was very low. 
(A. apricans) nimellä on näissä julkaisuissa esitetty kaksi lajia, apilanirppu (A. apricans) ja pieni apilanirppu (A. assimile).

151 näytteen mukana saatiin myös ilmoitukset näytenurmien iästä ja tämän perusteella voitiin selvitellä myös nurmen iän vaikutusta apilanirpun ja pienen apilanirpun runsauteen. Ilmeni, että kummankin lajin runsaus on sitä suurempi mitä vanhempia nurmet ovat (kuva 3).

Lounaista apilanirppua tavattiin ainoastaan yhdessä, Paraisista (LounaisSuomen saaristo) otetussa näytteessä. Tämä näyte on aikoinaan joutunut metsänhoit. Y. Kankaan haltuun, eikä eri nirppulajien runsaudesta ole tietoa.

Keltasäärinirppua esiintyi vain pienessä osassa näytteitä. Yksilöitä oli kaikkiaan 22 eli 0.1 yksilöä näytettä kohti.

Korvakekärsäkästä (Phytonomus nigrirostris Fabr.) tavattiin miltei joka toisessa näytteessä. Yksilömäärä oli vähäinen, vain 1.5 yksilöä näytettä kohti.

Mykerökärsäkästä (Phytonomus meles Fabr.) oli vain 16 näytteessä 14 pitäjän alueella (kuva 4). Yksilömäärä oli varsin vähäinen, keskimäärin 0.2 yksilöä näytettä kohti.

Apilan siemensääski (Dasyneura leguminicola Lintn.). Aikoinaan tehdyistä muistiinpanoista ilmeni, että lukuisista näytteistä oli löytynyt pieniä, punertavia sääskitoukkia. Lajia ei ollut määritetty eikä toukkia talletettu. Kesällä 1958 Tuhocläintutkimuslaitokselle hankitussa puna-apilan mykerönäyteaineistossa oli erittäin runsaasti apilan siemensääsken toukkia, ja ne olivat näytteiden sisältämistä

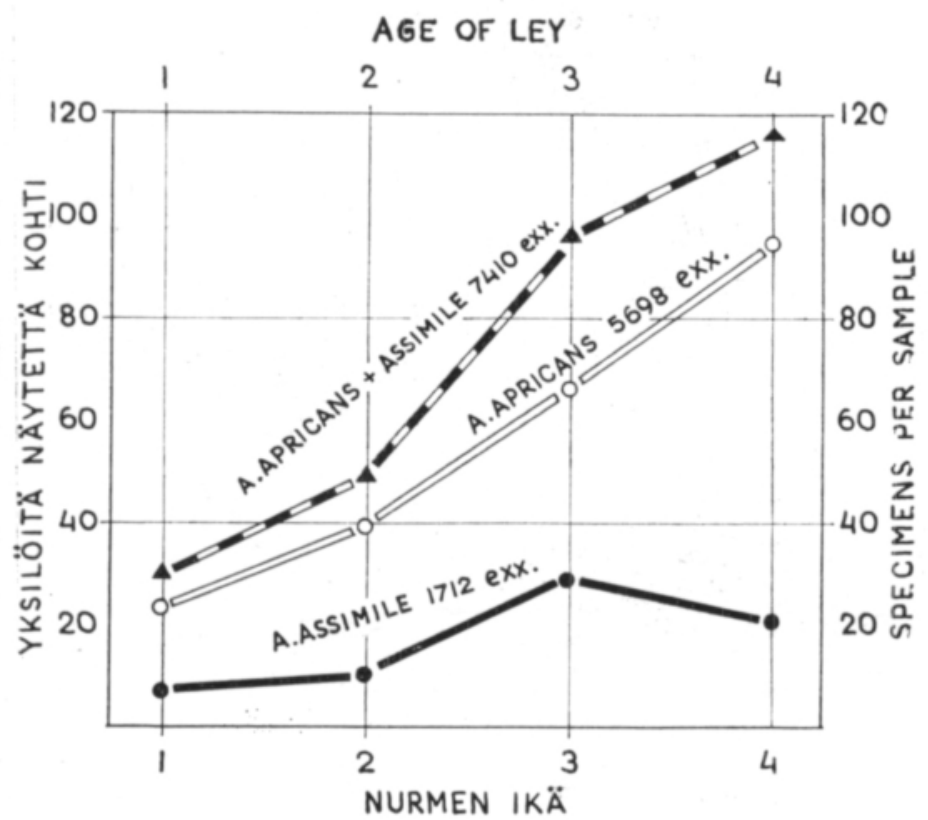

Kuva 3. Nurmen iän vaikutus apilanirpun (Apion apricans) ja pienen apilanirpun (A. assimile) runsauteen. Yksilörunsaus mykerönäytettä (100 mykeröä) kohti eri-ikäisillä nurmilla.

Fig. 3. Effect of the age of the ley upon the abundance of clover weevils (Apion apricans and A. a ssi mile). The number of individual weevils per sample of 100 heads is shown for leys of different ages. 


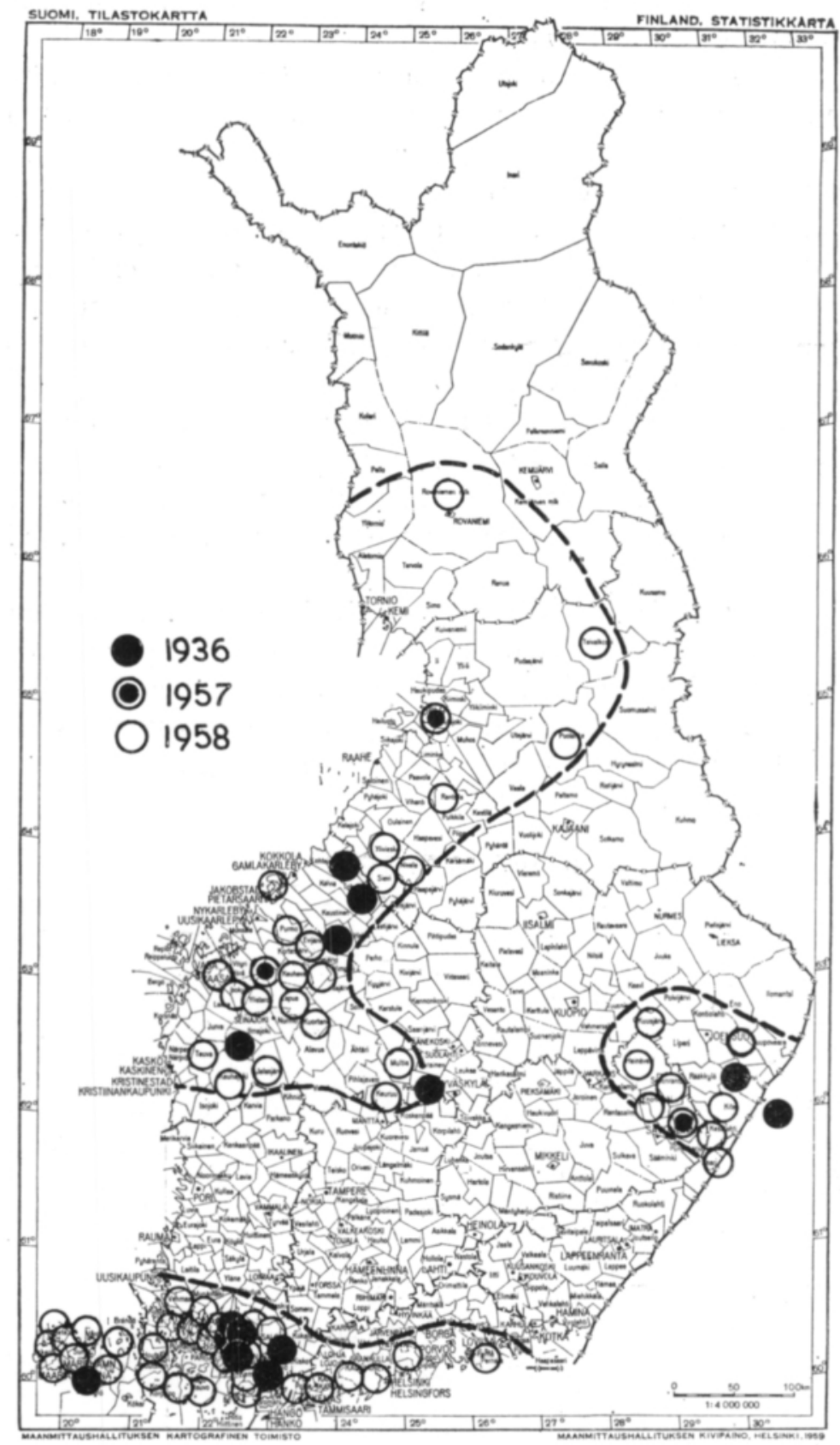

Kuva 4. Mykerökärsäkkään (Phytonomus meles) esiintyminen v:n 1936 mykerönäytteissä. Vertailun vuoksi on karttaan merkitty esiintymistiedot vuosien 1957 ja 1958 näytteistä. Lajin levinneisyysalueita rajoittava katkoviiva on MARKKULAn julkaisusta (1).

Fig. 4. Occurrence of the clover head weevil $P$ hy to no $m$ u's me les in the 1936 samples. As comparison the occurrence of this pest in the 1957 and 1958 samples is also shown in the map. The dotted line indicating the limit of the distribution of this species is from the publication of MARKKULA (1). 
sääskitoukista ylivoimaisesti yleisimpiä (1). V:n 1936 aineistossa on ilmeisesti ollut kysymyksessä sama laji.

Apilaripsiäinen (Haplothrips niger Osb.). Osassa näytteitä oli ollut melko runsaasti lajin toukkia, mutta tarkemmat muistiinpanot niiden esiintymisestä puuttuvat.

Näytteissä oli muistiinpanojen mukaan ollut lisäksi jonkin puna-apilan tuholaisena esiintyvän pikkuperhosen toukkia sekä mm. pistiäisiä, joista ilmeisesti enemmistö on ollut Apion- ja Phytonomus-lajien parasiitteja ja hyperparasiitteja.

\section{Tulosten tarkastelu}

Tulokset vastaavat hyvin Tuhoeläintutkimuslaitokselle v. 1958 hankitun, lähes 700 puna-apilan mykerönäytettä käsittävän aineiston antamia tuloksia (1). Joitakin pieniä eroavuuksia on kuitenkin todettavissa. V:n 1936 aineistossa apilanirpun ja pienen apilanírpun yhteenlaskettu runsaus 100 mykeröä kohti oli noin kolminkertainen v:n 1958 aineistoon verrattuna. Tällainen runsauden eroavuus mahtuu lajien normaalin runsaudenvaihtelun puitteisiin. Toisaalta on kuitenkin mahdollista, että mainitut lajit ovat esiintyneet lämpimällä 1930-luvulla runsaslukuisempina kuin viime vuosina. KANERvo (suull.) on tehnyt tähän viittaavia havaintoja.

Pienen apilanirpun prosenttinen osuus sen ja apilanirpun yhteismäärästä oli v:n 1936 aineistossa $(24.6 \%$ ) hieman pienempi kuin v:n 1958 aineistossa $(30.5 \%)$. Tämä johtuu ainakin osaksi siitä, että v:n 1936 aineistossa ei ole näytteitä PohjoisSuomesta, missä (Peräpohjolan maanviljelysseuran alueella) laji oli v. 1958 erittäin runsaslukuinen.

Molemmissa aineistoissa oli mainittujen lajien yhteenlaskettu yksilömäärä suurin Keski- ja Itä-Suomessa sekä pienin Länsi-Suomessa. Runsauden huippu keskittyi v. 1936 maan keskiosiin ja v. 1958 itäosiin.

Molempien vuosien aineistot osoittavat apilanirpun ja pienen apilanirpun yksilömäärän lisääntyvän nurmien vanhetessa. Runsauden lisääntymisessä on eräitä eroja, mutta ne johtuvat osaksi siitä, että vuoden 1936 aineistossa ei ole näytteitä maan pohjoisosista.

Lounaisen apilanirpun ainoa esiintymispaikka jää maamme lounaisimmassa osassa saman alueen sisään, josta v:n 1958 näytteissä saatiin lajin aikuisia. Keltasäärinirppua oli kumpanakin vuotena puna-apilan mykerönäytteissä sangen vähän. Lajin tärkeimpiä ravintokasveja ovat alsike- ja valkoapila. Kokeellisesti ei ole voitu osoittaa, että se kykenisi lisääntymään puna-apilassa (2). Laji on maassamme apilassa esiintyvistä lajeista liikkuvaisin ja herkin lentämään (3). Näin ollen on todennäköistä, että se on aikuisasteella joutunut puna-apilan mykerönäytteisiin. Myös NotıNı (4) on saanut lajin aikuisia puna-apilan mykeröistä.

Korvakekärsäkkään runsaus oli kumpanakin vuotena suunnilleen sama. Mykerökärsäkkään esiintymispaikat olivat v. 1936 samoilla alueilla kuin v. 1958 (kuva 4). Lajin mielenkiintoinen levinneisyys kaipaa lähempää selvittämistä. 
V:n 1958 mykerönäyteaineisto osoittaa apilan siemensääsken ja apilaripsiäisen levinneen myös Pohjois-Suomeen, mistä v. 1936 ei ollut näytteitä. Myös muiden siementuholaisten levinneisyyden pohjoisraja, lounaista apilanirppua lukuun ottamatta, ulottuu osaksi hyvinkin kauas sen alueen pohjoispuolelle, jolta on v. 1936 saatu näytteitä (1).

\section{Yhteenveto}

Etelä- ja Keski-Suomesta v. 1936 hankitussa puna-apilan mykerönäyteaineistossa esiintyi seuraavia puna-apilan siementuholaisia: apilanirppu (Apion apricans Herbst), pieni apilanirppu (A. assimile Kirby), lounainen apilanirppu (A. trifolii L.), korvakekärsäkäs (Phytonomus nigrirostris Fabr.), mykerökärsäkäs ( $P h$. meles Fabr.), apilan siemensääski (Dasyneura leguminicola Lintn.) ja apilaripsiäinen (Haplothrips niger Osb.) sekä lisäksi jonkin verran keltasäärinirppua (Apion flavipes Payk.), joka kuuluu alsike- ja valkoapilan siementuholaisiin. Apilanirppu ja pieni apilanirppu olivat runsaslukuisimpia. Niiden yhteenlasketusta yksilömäärästä oli ensin mainittua $3 / 4$ ja viimeksi mainittua $1 / 4$. Lajien runsaus oli suurin maan keski- ja itäosissa. Kummankin lajin yksilömäärä oli sitä suurempi mitä vanhempia nurmet olivat. Tuloksia on verrattu Tuhoeläintutkimuslaitokselle v. 1958 hankitun vastaavanlaisen mykerönäyteaineiston antamiin tuloksiin ja todettu ne määrätyissä rajoissa toisiaan vastaaviksi.

\section{KIRJALLISUUTTA}

(1) Markкula, M. 1959. Puna-apilan siementuholaisten levinneisyys, runsaus ja tuhoisuus Suomessa sekä tuhojen torjunta. Summary: The distribution, abundance, and injuriousness of the seed pests of red clover in Finland and the control of the damage. Valt. maatal.koet. tied. (Rep. Finnish Sta. Agric. Res.) 239: 1-27.

(2) - \& MүLцумӓкI, S. 1957. Investigation into the oviposition on red and alsike clover and alfalfa of Apion apricans Herbst, A. assimile Kirby, A. flavipes Payk., A. seniculus Kirby, and $A$, virens Herbst (Col., Curculionidae). Ann. Ent. Fenn. 23: 203-207.

(3) $\rightarrow$ \& MYllyмäкi, S. 1958. The composition of the Apion (Col., Curculionidae) population of grassland legumes and some wild leguminous plants. Ibid. 24: 97-124.

(4) NotıNı, G. 1935. Undersökningar rörande på rödklöver levande spetsvivlar (A pion Herbst). 1. Deras förekomst, levnadssätt och utvecklingshistoria. Statens Växtskyddsanstalt, Medd. 9: $1-63$.

(5) VAlle, O. 1936. Apilanirppu (Apion apricans) puna-apilan siementuhoojana. Suom. Laiduntal. 7: $96-102$.

(6) — 1936. Untersuchungen zur Bekämpfung von Samenschädlingen verschiedener Kleearten. Matal.tiet. aikak. (Journ. Sci. Agric. Soc. Finl.) 8: 195-209.

(7) —— 1938. Puna- ja alsikeapilan siementuotannon kehittämisestä. Tammistossa suoritettuja tutkimuksia 1933-1937. Hankkijan kasvinjalostuslaitos Tammisto, Siemenjulkaisu 1938: $180-190$. 
S U M M A R Y: THE OCCURRENCE AND ABUNDANCE OF INSECT PESTS OF RED CLOVER IN FINLAND
IN 1936

Martti Markkula and Otto Valle

Agricultural Research Centre, Department of Pest Investigation and Department of Plant Husbandry, Tikkurila

The article discusses results obtained in 1936 from red clover head material collected in southern and central Finland (188 samples from 111 communes, each sample containing 100 flower heads). The following insect pests were found in the samples: Apion apricans Herbst, A. assimile Kirby, A. trifolii L., Phytonomus nigrirostris Fabr., Ph. meles Fabr., Dasyneura leguminicola Lintn. and Haplothrips niger Osb.; in addition the species Apion flavipes Payk., which is ordinarily a pest of alsike and white clover, was also present to some extent. The most abundant species of these pests were the clover weevils Apion apricans and $A$. assimile, reaching a total of 10739 individuals. The former weevil comprised three-fourths of this number and the latter one-fourth. These species were most abundant in the central and eastern parts of the country and were found in increasing numbers as the age of the ley increased. The results are compared to those obtained in 1958 from corresponding red clover head material collected by the Department of Pest Investigation and are found within certain limits to be closely similar. 